\title{
Experiential Learning: Using Virtual Simulation in an Online RN- BSN Program
}

\author{
Henny Breen \\ Linfield College - Portland Campus Nursing \& Online and Continuing Education \\ Melissa Jones \\ Linfield College - Portland Campus Nursing \& Online and Continuing Education
}

Follow this and additional works at: https://digitalcommons.linfield.edu/nursfac_pubs

Part of the Health and Physical Education Commons, Nursing Commons, Online and Distance Education Commons, and the Public Health Education and Promotion Commons

\section{DigitalCommons@Linfield Citation}

Breen, Henny and Jones, Melissa, "Experiential Learning: Using Virtual Simulation in an Online RN-BSN Program" (2015). Faculty Publications. Accepted Version. Submission 1.

https://digitalcommons.linfield.edu/nursfac_pubs/1

This Accepted Version is protected by copyright and/or related rights. It is brought to you for free via open access, courtesy of DigitalCommons@Linfield, with permission from the rights-holder(s). Your use of this Accepted Version must comply with the Terms of Use for material posted in DigitalCommons@Linfield, or with other stated terms (such as a Creative Commons license) indicated in the record and/or on the work itself. For more information, or if you have questions about permitted uses, please contact digitalcommons@linfield.edu. 
Experiential Learning: Using Virtual Simulation in an Online RN-BSN Program

\begin{abstract}
This article highlights the innovative experiential learning used by an online RN-BSN program through the use of simulation that takes place in an online classroom. Three experiential learning activities using a virtual community are described. These learning activities engage the students in thinking about social justice and health policy as well as teaching concepts that include community, leadership, influence, advocacy, networking, collaboration, and vulnerable populations. These concepts are critical to the learning needs of diploma and associate degree-prepared nurses who wish to continue their education to be better prepared to meet the complex needs of today's healthcare environment.
\end{abstract}

Key Points

1. RN to BSN programs build on diploma and associate degree programs with course work that facilitates professional development and a better understanding of the cultural, political, economic, and social issues that impact patients and health care delivery.

2. Vital to the learner in the online RN-BSN program is collaborative learning as much of the learning is enhanced through collaborative written discourse.

3. Virtual simulation meets the experiential learning needs of adult learners who need flexibility given the demands on their time and the shortage of clinical sites. 
The purpose of this article is to highlight the innovative experiential learning used by an online RN-BSN program through the use of simulation that takes place in an online classroom. The demands of today's healthcare environment requires nurses to have a broader knowledge base which goes beyond technological competence, to include abilities in leadership, health policy, system improvement, research and evidence-based practice, teamwork and collaboration (Institute of Medicine [IOM], 2011; Smith, 2009). In addition to this broad based knowledge, competency in specific content areas such as public health with a greater orientation to community-based primary care and an emphasis on health promotion are required (IOM, 2011).

In response to this need, a small liberal arts college in the Pacific northwest in the United States developed an online RN-BSN program that is community and concept-based, emphasizing leadership, health promotion, illness prevention and treatment, and social justice, through a learner-centered approach to nursing education. In recent years, several schools of nursing have adopted concept-based curricula as a framework that is well-supported in the literature. The advantages of this approach to nursing education include a more streamlined approach to managing content, a student-centered approach to teaching, and enhanced critical thinking on behalf of students (Giddens et al., 2008; Giddens \& Morten, 2010). A learnercentered approach to education is a framework that provides the opportunity for students to engage in discourse about complex issues that emerge in higher education (Dolence, 2003). This approach is integral to the online program as students engage in collaborative written discourse in all of the courses.

RN to BSN programs build on diploma and associate degree programs with course work that facilitates professional development and a better understanding of the cultural, political, economic, and social issues that impact patients and health care delivery. Online education is recognized as offering the flexibility needed for practicing associate degree (ADN) and diploma-prepared Registered Nurses to return to school to earn their BSN (IOM, 2011). As a result, online learning in nursing education has been evolving at a rapid pace (Billings \& Halstead, 2009). Providing experiences that enhance this learning is critical to the nurses' career development as they continue their education. Many schools of nursing report challenges 
involved in securing clinical teaching sites for their nursing students driving the need for innovative teaching strategies that meet student needs for experiential learning.

\section{RN-BSN Program}

Approximately 150 Registered Nurses enter the online program each year and 324 nurses graduated with their BSN between 2010 and 2013. The majority of nurses that attend the program are employed in nursing and bring a variety of personal and professional experiences to the online classroom as they continue their education to meet the demands of today's healthcare environment. To enhance the student's continuing education, the faculty who teach in the RN-BSN program are committed to a constructivist pedagogy based on constructivist-learning theory. Constructivist-learning theory suggests that learning is an active process in which learners make meaning of new information and construct new knowledge through experience and reflection upon that experience (Harasim, 2012; Jahng, Nielsen, \& Chan, 2010). This is vital in a program in which much of the learning happens through students engaging with the course content by reflecting on new knowledge and integrating it with their previous knowledge, nursing practice and personal experiences.

Further and equally vital to the learner in the online RN-BSN program is collaborative learning as much of the learning is enhanced through collaborative written discourse. Collaborative learning is an active process in which learners make meaning of new information and construct new knowledge with a group of knowledgeable peers rather than constructing new knowledge alone (Guilar \& Loring, 2008; Jahng, Nielsen, \& Chan, 2010).

A unique feature of this program is the final course, Integrated Experiential Learning (IEL), as it integrates all the previous learning in the program using three main strategies to meet the student learning needs. The strategies include: (1) clinical experience with a preceptor who is a nurse leader, (2) professional development activities that are negotiated between the student and instructor, and (3) three experiential learning activities using a virtual community. The three virtual learning activities use collaborative learning theory to guide the student's engagement in the activity along with other theoretical orientations or strategies. 


\section{Integrated Experiential Learning (IEL) Course}

Three learning activities using the virtual community, "The Neighborhood" developed by Jean Giddens are highlighted with emphasis on the learning outcomes and student evaluation of their own learning. The Neighborhood features unfolding stories of several characters representing community and nurse members. The stories are enhanced with pictures, video clips, medical records, and newspaper clippings (Giddens, 2010). Students are required to become familiar with the community throughout the course and completed an orientation scavenger hunt for The Neighborhood in order to participate in the learning activities. The three learning activities in the IEL course include a clinical reasoning assignment, a disaster-nursing case study, and a coalition-planning document. All three learning activities are intended to meet the higher level learning required by BSN graduates identified earlier such as leadership, health policy, system improvement, research and evidence-based practice, teamwork and collaboration.

\section{Clinical Reasoning}

An activity using clinical reasoning was chosen in order for the student to demonstrate higher-order thinking in providing nursing care. Clinical reasoning is influenced by the nurse's attitude, preconceptions, philosophical perspective and ability to think critically. Thus, clinical reasoning requires the nurse to master higher order thinking skills that can be achieved through the development of critical and reflective thinking that requires the self-regulation of cognitive and metacognitive thinking in nursing practice (Kuiper \& Pesut, 2004). Throughout the program, the students are challenged to develop these skills through the use of collaborative discussion, reflective practice journal writing, and written assignments. This is consistent with constructivist pedagogy and collaborative learning as learning occurs individually through interactions with others in which the learners share, construct, and reconstruct their ideas and beliefs (Chikotas, 2008).

Students are provided with an overview of the Outcome-Present-State Test clinical reasoning model that is used by the School of Nursing. The Outcome-Present-State Test (OPT) model of clinical reasoning is a third generation nursing process meta-model. The OPT is designed to assist students in planning and evaluating their nursing care by building on prior 
knowledge in an iterative fashion to further develop their nursing thinking skills (Kautz et al., 2009; Bartlett et al., 2008). The authors of the model, Pesut \& Herman based the model on Bandura's self-efficacy learning theory that postulates that the student's problem solving skills improve if they see that their actions make a positive difference (as cited in Kautz et al., 2009). As students understand how nursing diagnoses, nursing actions, and making judgments about the care they provide makes a difference in moving a patient from their current state to a desired outcome, their ability to clinically reason improves (Kautz et al., 2009).

Clinical reasoning activity. The students are required to use the model in addressing the needs of one member or family of their choice from the virtual community. As they are working on developing their individual plan, they have the option to collaborate with each other to learn from each other's expertise as practicing nurses. This learning activity highlights both their cognitive and metacognitive thinking by articulating their reasoning that includes patterns, filters, and assumptions as they write the client story gleaned from The Neighborhood. From this they develop two nursing diagnoses, specific nursing and collaborative actions, which require other healthcare providers within the virtual community, to meet the client's needs, and potential risks from these actions. The students follow this model using nursing judgment to assess patient outcomes. Following the development of their plan for the virtual community member, the student reflects on their learning including how they used evidence-based strategies and ethical reasoning to provide nursing care.

\section{Disaster Nursing}

Disaster nursing was chosen as an exemplar activity for teaching concepts in the IEL course that included community, collaboration, leadership, and vulnerable populations. The IEL course provided an opportunity to engage more fully in the previously learned concepts by using experiential learning activities such as a simulated disaster. A problem-based learning (PBL) approach was used in the development and delivery of the simulated disaster experience.

Problem-based learning (PBL) is a strategy that has been used to enhance collaboration among students while recognizing the prior knowledge and experiences of adult learners (Chikotas, 2008). Adult students appreciate a relevant approach to education that is immediately applicable to their life and work. In nursing education, PBL has provided practical 
and effective learning experiences such as case studies, problem-solving exercises, and service-learning experiences (AACN, 2010).

In an experimental study which compared PBL and conventional teaching in an undergraduate nursing program, Lin, Lu, Chung, and Yang (2010) identified PBL as an organized, student-centered educational strategy. The results demonstrated evidence of learning effectiveness for both groups, however, the PBL group was found to be more effective. Students who participated in PBL reported higher satisfaction with skills in self-motivation and critical thinking when compared to the group who participated in conventional teaching (Lin et al., 2010). The researchers also found that the distance between the students' developmental level and their potential was supported by engaging in a socially interactive process of problem solving that was influenced by the skills and abilities of each student. When developing the disaster nursing activity, the previous knowledge and experience of the RN-BSN students was considered. In addition, opportunities for interaction and peer collaboration were purposely integrated.

Disaster learning activity. To prepare for their work during the disaster in the virtual community, students completed all their reading assignments for The Neighborhood. At the start of the activity, an announcement was placed in the course to notify students that a disaster had taken place in the virtual community. One example of an announcement that was used for a simulated earthquake is as follows:

\section{EARTHQUAKE STRIKES THE NEIGHBORHOOD}

A magnitude 6.8 earthquake struck the Neighborhood Community early this morning. Residents are warned to stay away from buildings that appear loosened from the initial earthquake due to the risk posed by aftershocks. Many of the residents of the Neighborhood have been displaced from their homes. Your work assignment today is working as a community/public health nurse and you are to report immediately to the Neighborhood to care for the residents and assist your colleagues in addressing this disaster. Please let me know if you have any questions. Have fun! At the same time, the learning module for this learning activity is opened.

To supplement The Neighborhood, video clips of past earthquakes are posted to give the students a visual picture of the disaster. Resources regarding disaster nursing are provided such as peer-reviewed articles about the nurse's role in disasters and the International Council of Nursing Framework of Disaster Nursing Competencies. The students are instructed to roleplay being a community health nurse and to collaborate with each other in providing care to the families who have been 
impacted by the disaster. As the students engaged in their roles, several themes and topics began to surface. Some of the topics included communication issues such as cell phone batteries dying and access to ham radios; missing and/or displaced persons; resources such as the role of Red Cross, Federal Emergency Management Agency and the Coast Guard; triage and transportation including START (simple triage and rapid transport); challenges regarding accessing resources such as oxygen supply for a patient with COPD, electricity, generators; where to set up a safe shelter; damage to the community hospital; stress and loss; and the need for debriefing and support for their nurse colleagues as they cared for others. In their role as community health nurse, the students also engaged with other community partners such as teachers, law enforcement, physicians and other health care providers, and other volunteers.

Following the role-play activity students engaged in a more formal discussion in which they researched and shared information about leadership in a disaster, recovery and rehabilitation, ethical, legal, and accountability issues, as well as an assessment of the virtual community in terms of the resources needed to care for the community during a disaster. The following is an example of a discussion question with a prelude to the question.

Hurricane Katrina was one of the deadliest storms to ever reach the shores of the United States (Priest \& Bahl, 2008). This storm devastated New Orleans and left its hospitals in utter chaos, hospitals were barely able to provide staff to provide minimal care and those who were available worked under the most extreme circumstances (Priest \& Bahl, 2008). Following the devastation, a doctor and two nurses were arrested for concerns related to alleged "euthanasia" of patients at Memorial Medical Center (see newspaper article in the learning module).

Describe the details of this situation; be sure to include the impact on patients, hospital personnel, and the community.

Analyze the key ethical, legal, and accountability issues that the nurse should be aware of during a disaster.

In addition to the role-play, this activity has been implemented by requiring that students develop a nursing action plan for one individual or family in The Neighborhood. The individuals and families chosen for this activity included specific vulnerabilities, including an elderly couple who became displaced from their home as a result of the disaster. In this particular example, students used their action plan to identify how they would prioritize the needs of the elderly couple. Examples of their planning included how they would connect the couple with family members who could take them in, how they would obtain necessary medications, meet their physical health needs, and how they could ensure their immediate safety in the 
community. Through addressing the vulnerabilities of individuals in the community during a disaster, students developed additional interest and even formed bonds with the characters. The emotional engagement in the activity is expected to heighten the memory of the learned material (Zull, 2004). In addition, the context diversity that is achieved through engaging in multiple communication and interactive modes during the disaster allows students to benefit from lived experience rather than reading an isolated case study (Carlson-Sabelli, Giddens, Fogg, \& Fiedleer, 2011).

\section{Coalition Building}

Coalition building for homeless veterans was chosen as an exemplar activity for engaging the students in thinking about social justice and health policy as well as teaching concepts in the IEL course that included community, leadership, influence, advocacy, networking, collaboration, and vulnerable populations. Coalitions are defined as "an alliance of people or groups with similar goals who join to achieve their objectives" (Sullivan, 2004, p. 90). Conducting this work in smaller groups of three to five students was chosen because smaller groups provide the time and space available for each learner to express their ideas (Boettcher, Conrad, 2010). In addition, small groups allow each student to contribute substantially to the final product. Faculty are also able to assess leadership skills when students work in small groups such as collaborating for the purpose of producing a group product requires decisions to be made about how students will work together (Breen, 2014).

Homeless veterans were chosen as an exemplar to meet the Joining Forces pledge taken by Linfield-Good Samaritan School of Nursing (LGSSON) in 2013. The pledge was taken to join the American Association of Colleges of Nursing (AACN), the Department of Veteran Affairs, the American Nurses Association, the National League for Nursing, the National Organization for associate Degree Nursing, and other stakeholders that urged nursing schools across the United States to support the national initiative led by First Lady Michelle Obama and Dr. Jill Biden. By pledging their support, nursing schools agreed to enhance the education and preparation of the nation's nurses to care for veterans, service members, and their families (AACN, 2014).

Planning document for a community coalition activity. To prepare for the activity, students in an early learning module discuss how they can influence community change through the use of coalitions. They initially discuss an issue that is 
important to them and how they would start a coalition to address the issue using their influence as registered nurses. The students are provided with information about evidence-based practices for coalition building and examples of successful coalitions. Being able to choose an issue that is important to them engages them as it has special meaning.

Information about homeless veterans is provided along with a review about coalition building and planning steps for the development of a coalition. The students work in a wiki to facilitate collaboration amongst the group members. Working in a wiki permits group members to contribute and modify the document. Changes and additions are tracked (Wikis, 2013). The students in small groups are instructed to develop a planning document for a community coalition in The Neighborhood for an underserved population, namely homeless veterans. The planning steps for the community coalition were an adaptation of a quality improvement process. They include identifying the values of the community; creating a vision statement; identifying the needs of the stakeholders; collecting data from The Neighborhood to measure the current status of services for homeless veterans and to identify assets and physical elements of the community that could be used; establish measurable outcomes and quality indicators and how the data will be collected and evaluated for each outcome or indicator; and develop a plan to implement and meet the outcomes (Folse, 2014).

\section{Student Evaluation}

The students were asked to provide feedback about how the virtual learning activities including when they felt the most engaged or interested in activity, the concepts they will apply to their practice, and how their work with vulnerable populations was or was not influenced by their involvement in the learning activity. Student feedback was evaluated for evidence of meeting the learning goals of each activity.

Clinical reasoning. The goal of the clinical reasoning activity was to provide an opportunity for the students to demonstrate higher-order thinking in providing nursing care, thereby, increasing confidence that their actions will move the patient from their current state to a desired outcome. The following comments reflect greater confidence and higher-order thinking in developing a plan.

This provided me with an opportunity to ... reflect on potential outcomes, interventions, and rationales behind the care. This assignment provided me an opportunity to put thought and rationale into the care plan versus clicking on premade 
categories and interventions that is used in developing care plans in most EMR's that I have used in the acute care settings.

I have already begun watching patient's faces closely as their family talks to me, or as they talk to their families. In two situations already what I have seen has caused me to go back to the patient when the family has gone and ask them to clarify the plan - just to make sure I have it right. In both cases I got the "I know what he/she said, but..." response. Even in situations where a spouse is clearly the official spokesperson for the patient, that patient may still have other ideas about how it is really going to be.

I will continue to seek evidence based and best practice knowledge to guide my decision making in clinical practice.

The students also gained a renewed and deeper appreciation for the patient in the context of their social situation.

Each patient had medical problems and social issues. Social issues such as living conditions, work environment, and lack of social support are an important part of one's health. I can apply the importance of assessing my patients' social issues to my nursing practice. Acceptance of what the patient's own needs are as being the most important to address, instead of assuming we know what they will need/would help most. Collaboration is the key to success and satisfaction.

The stories of the characters in the neighborhood community were detailed and the factors that make people vulnerable were discussed. For example, the character I worked on had many factors such as having a chronic disease, having disabilities, losing health insurance, losing a job, and being poor. It was interesting to learn how each problem contributed to other problems such as losing a job caused the character to lose health insurance and be poor. The way that disabilities make people vulnerable was something that increased my sympathy towards people with chronic disease and their families.

Be more compassionate of patients and their families. Realize that the glimpse I get to see during my short time with them in the OR is just a fraction of the entire picture of their lives. I therefore, have no right to judge in any way, shape or form that which is different from what I would choose for myself.

Disaster nursing. The primary goals of the disaster nursing activity were for the students to apply the concepts of community, collaboration, leadership, and vulnerable populations. The concepts of community, collaboration, and leadership are evident in the following written comments made by a number of different students: "reading about the health issues of the characters helped me to develop a concept that a community is built with people who have various needs"; "I plan on putting together a disaster preparedness kit for my family, and it has made me do a lot of thinking about my own community and what our vulnerabilities would be in a disaster"; “..the assessment of the community's resources and the ideas of preparedness on the individual and career level”; “...it made me think about being more involved on a local level and maybe volunteering for the Medical Reserve Corp"; "I think this has increased my awareness of the importance of community involvement, networking, 
and political involvement in coalitions for disaster preparation"; "I am more interested in being involved in planning, and becoming a member of the coalition for disaster preparedness"; and "the virtual role-playing made me think about my leadership role in this scenario...I was able to picture myself in the disaster and that helped me think and learn. I also learned from my other group members."

The students gained a deeper appreciation for vulnerable populations through the disaster nursing activity as reflected in the following comments.

I saw new vulnerabilities in everyone and new strengths too. Stable people became needy when faced with illness, injury, or the death of a loved one, and 'vulnerable' people showed that they had skills to offer and the willingness to do so to help others. This underscores the creativity required when planning for disaster response - the helper helpee may change places!

It helped me to read about the members of the community who had disabilities and other health problems. Having to help those individuals virtually increased my interest in reaching out to the vulnerable population especially when times are difficult such as in a bad economy, harsh weather, and a disaster because they are affected by the difficulties more.

The disaster plan case study taught me that nurses play a great role in disaster relief and taking care of the vulnerable populations in times of disaster. It is important for nurses to have critical thinking skills, communication skills, assessment skills, and technical skills.

A greater awareness of the additional struggles these people face. For the vulnerable population, even a minor disaster in society can mean devastation to those without resources. These troubles can be compounded exponentially in this group, and having an impact on society and the individual for years. Even though I knew these things, I was reminded how hard life can be for some people. This is information I can incorporate into my teaching to employees.

Additionally many of the students commented on the need to be better prepared for a disaster. For example, "I plan on putting together a disaster preparedness kit for my family" and "...understanding of the challenges in large scale situations has encouraged me to encourage others to make efforts towards basic preparedness needs, such as canned food and water".

Coalition building. The goal of this learning activity was to have students thinking about social justice and health policy using homeless veterans as the exemplar as well as the concepts of community, leadership, influence, advocacy, networking, collaboration, and vulnerable populations. The following comments reflect the student's perception that the goals of this activity were met: "It was a great learning experience to collaborate with other nurses to provide help for the homeless veteran population.... and provided a great team-work opportunity; “The Veteran Coalition project opened my 
eyes to how bad veteran homelessness is. As a nurse, if I ever cared for a homeless veteran, I would better understand their situation, and the resources available to assist them"; and "The importance of working together for the common good of the community and patient". Other comments included:

I have new knowledge how to set up a coalition and delegate sections of work. Also, I have learned how to collaborate with team members, with focus on change in the community to help individuals.... In addition, I am more aware and understand how PTSD affects individuals involved in war.

I have learned quite a bit about coalitions .... One experience is that coalitions need to have goals related to all members not just from one person's perspective-each member may have a different interest in how to help the community.

The goal must be narrow enough to be manageable. There is a tendency to try to solve all problems at once resulting in no problems being solved at all. This is particularly true of the homeless Veterans issue, which is multifactorial.

I am able to be a productive coalition member by researching, interviewing, and creating plans to help vulnerable populations. In addition, I realize becoming knowledgeable of vulnerable individuals within a community requires research, interviews, surveys, etc. to know how to approach an effective plan.

It has increased my awareness of local coalitions and what they provide for the community members who may be at risk. I have learned to explore more of the community resources and how important networking can be in providing care to at risk individuals

Research on this coalition project opened my eyes to the staggering statistics about homeless Veterans. Even in my work at the Veterans Hospital I did not know many of the facts that came to light. I have been sharing what I have learned with the nurses at my facility to give them a greater understanding of the struggles of our Veteran patients.

\section{Conclusion/Recommendations}

The three learning strategies using a virtual community were developed to meet the experiential learning needs of diploma and associated degree-prepared registered nurses who are continuing their education in order to advance their career. The primary goal of the activities was for the students to demonstrate a broader knowledge base, which goes beyond technological competence, to include abilities in leadership, health policy, system improvement, research and evidence-based practice, teamwork, collaboration, and a greater orientation towards community-based care (Institute of Medicine, 2011; Smith, 2009). Evaluation of the activities confirms that the goals were met and are recommended for use in other online programs.

Based on student and faculty experience over several semesters, the following recommendations are suggested. 
1. Different types of disasters are more prevalent in different regions of the country and world. In the northwest of the United States, concerns about a major earthquake are more prevalent. In other parts of the country, hurricanes, tornadoes, flooding are more of a concern. The simulated disaster could be changed to reflect the community that most of the students reside in. Other potential disasters could include technical or man-made disasters such as famine, industrial accidents or chemical weapons.

2. The exemplar of homeless veterans was chosen in response to LGSSON's Joining Forces pledge. Other exemplars could be used or students could choose their own social justice issue based on issues that are important to the group members.

3. The use of role-playing as an effective teaching strategy that engages students in the context of real-life scenarios.

4. The use of the virtual community as an effective learning strategy that uses technology to support learning and practice in nursing. The virtual community is recommended for engaging other student populations, such as traditional BSN students, in exploring complex concepts. 


\section{References}

American Association of Colleges of Nursing. (2010). Lifelong learning in medicine and nursing: Final conference report. Retrieved from http://www.aacn.nche.edu/education-resources/MacyReport.pdf

Bartlett R., Bland A., Rossen E., Kautz D., Benfield S., \& Carnevale T. (2008). Evaluation of the Outcome-Present State Test Model as a way to teach clinical reasoning. Journal of Nursing Education, 47(8) 337-344. doi: 10.3928/0148483420080801-01

Billings, D. M., \& Halstead, J. A. (2009). Teaching in nursing: A guide for faculty (3rd ed.). St. Louis, MO: Saunders-Elsevier. Boettcher, J. V., \& Conrad, R. M. (2010). The online teaching survival guide. San Francisco, CA: Jossey-Bass.

Breen, H. (2014). Assessing online collaborative discourse. Nursing Forum. doi: 10.1111/nuf.12091.

Carlson-Sabelli, L., Giddens, J., Fogg, L., \& Fiedleer, R. (2011). Challenges and benefits of using a virtual community to explore nursing concepts among nursing students. International Journal of Nursing Scholarship, 8(1), 1-14. doi:10.2202/1548-923X.2136

Chikotas, N. E. (2008). Theoretical links: Supporting the use of problem-based learning in the education of the nurse practitioner. Nursing Education Perspectives, 29(6), 359-362.

Dolence, M.G. (2004). The learner-centered curriculum model: A structured framework for technology planning. EDUCAUSE: Center for Applied Research Bulletin, 203(17). Retrieved from https://net.educause.edu/ir/library/pdf/erb0317.pdf

Folse, V.N. (2014). Managing quality and risk. In P.S. Yoder-Wise (Ed.), Leading and managing in nursing, (pp. 389-409). St. Louis, MO: Elsevier.

Giddens, J. (2010). The Neighborhood: Instructor's navigation guide. Boston: Pearson.

Giddens, J., Brady, D., Brown, P., Wright, M., Smith, D., \& Harris, J. (2008). A new curriculum for a new era of nursing education. Nursing Education Perspectives, 29(4), 200-204. 
Guilar, J., \& Loring, A. (2008). Dialogue and community in online learning: Lessons from Royal Roads University. Journal of Distance Education, 22(3), 19-40.

Giddens, J., \& Morton, N. (2010). Report card: An evaluation of a concept-based curriculum. Nursing Education Perspectives, 31(6), 372-377. doi:10.1043/1536-5026-31.6.372

Harasim, L. (2012). Learning theory and online technologies. New York: Routledge.

Institute of Medicine. (2011). The Future of Nursing: Leading Change, Advancing Health [Policy Report]. Washington, DC: The National Academies Press. Retrieved from http://thefutureofnursing.org/IOM-Report

Jahng, N., Nielsen, W. S., \& Chan, E. K. H. (2010). Collaborative learning in an online course: A comparison of communication patterns in small and whole group activities. Journal of distance Education, 24(2), 39-58.

Kautz, D., Kuiper, R.A., Bartlett, R., Buck, R., Williams, R., \& Knight-Brown, P. (2009). Building evidence for the development of clinical reasoning using a rating tool with the Outcome-Present-State-Test (OPT) Model. Southern Online Journal of Nursing Research, 9(1). Retrieved from http://www.resourcenter.net/images/SNRS/Files/SOJNR_articles2/Vol09Num01Art15.html

Kuiper, R. A., \& Pesut, D. J. (2004). Promoting cognitive and metacognitive reflective reasoning skills in nursing practice: Self-regulated learning theory. Journal of Advanced Nursing, 45(4), 381-391. doi: 10.1046/j.1365-2648.2003.02921.x

Lin, C., Lu, M., Chung, C., \& Yang, C. (2010). A comparison of problem-based learning and conventional teaching in nursing ethics education. Nursing Ethics, 17(3), 373-382. doi:10.1177/0969733009355380

Priest, C., \& Bahl, M. (2008). Nursing during catastrophic disaster: A case study from New Orleans. Journal of Nursing Law, 12(4), 157-164.

Smith, T. G. (2009). A policy perspective on the entry into practice issue. OJIN: The Online Journal of Issues in Nursing, 15(1). doi: 10.3912/OJIN.Vol15No01PPT01

Sullivan, E. J. (2004). Becoming Influential: A Guide for Nurses. Upper Saddle River, N.J. Pearson. 
Wikis (2013). Retrieved June 20, 2014 from https://help.blackboard.com/en-

us/Learn/9.1_SP 10_and_SP_11/Instructor/050_Course_Tools/Wikis

Zull, J. E. (2004). The art of the changing brain. Education Leadership, 62, 68-72. 